\title{
RELAXATION TECHNIQUES INTERVENTIONS DURING PHYSICAL EXERCISE CLASSES AND COPING WITH STRESS
}

original paper

() University School of Physical Education in Wroclaw

DOI: https://doi.org/10.5114/hm.2018.76078

\section{ANNA URBANSKA ${ }^{1}$, LESLAW KULMATYCKI ${ }^{2}$, KRYSTYNA BORON-KRUPINSKA ${ }^{2}$, KATARZYNA TORZYNSKA ${ }^{2}$}

${ }^{1}$ The Complex of Gastronomy Schools in Wroclaw, Wroclaw, Poland

${ }^{2}$ University School of Physical Education in Wroclaw, Wroclaw, Poland

\begin{abstract}
Purpose. The fundamental purpose of the study was to answer the questions if and to what degree the application of relaxation techniques during physical education (PE) classes influenced the capacity to cope with stress in comparison with traditional PE classes in a group of senior high school female students.

Methods. A pedagogical experiment was carried out by the technique of parallel groups in real-life environment. It involved 182 female students from a senior high school in Wroclaw, Poland, aged 16-18 years. The students were divided into 2 groups: the study group (122 students) and the control group (60 students). A standardized research tool - the Personal Competence Scale (KompOs) was used in pre-tests and post-tests to evaluate the capacity to cope with stress.

Results. The PE classes including relaxation techniques in comparison with traditional PE classes had a positive impact on coping with stress in the group of female students of senior high school age. During the period between the tests, an increase of the sense of power and perseverance factors was observed. The difference between the average values of the general sense of self-efficacy was not statistically significant when comparing the study group and the control group (at the beginning and at the end of the study).
\end{abstract}

Conclusions. In Polish schools, it is necessary to continue the research in the field of implementing various strategies and innovations in teaching PE classes with a focus on coping with stress.

Key words: relaxation techniques, coping with stress, school

\section{Introduction}

In the modern world, young people encounter an increasing number of various challenges. Owing to the excess of information or stimuli, which traditionally were available at later stages of life, higher expectations from parents, or lack of understanding on the part of adults, the adolescent are more stressed, neurotic, and susceptible to many psychosomatic conditions. In the past, problems related to depression used to concern adults only; today, they affect increasingly younger population. One of five children in the United Kingdom suffers from anxieties and/or depression [1].

Puberty is the stage of life when important developmental events impact the stress level and the emo- tional condition of a minor. Earlier studies show that young people who have problems with anger also experience a high level of stress and present health problems, such as hypertension [2], as well as interpersonal difficulties [3] or suicidal inclinations [4]. It has also been proven that there is a relationship between longterm stress or feeling unwell and the abuse of addictive substances, violence, and obesity [5].

Numerous pedagogues believe that school is the main factor causing anxiety and stress among children and youth [6]. The main sources of educational stress are related to learning difficulties and the organization of school life, or problems that concern establishing social relations with teachers and peers [7]. The group of school issues includes specific learning difficulties,

Correspondence address: Krystyna Boroń-Krupińska, Department of Social Sciences and Health Promotion, University School of Physical Education in Wrocław, al. I.J. Paderewskiego 35, 51-612 Wroclaw, Poland, e-mail: krystyna.boron@awf.wroc.pl

Received: October 12, 2017

Accepted for publication: December 4, 2017

Citation: Urbanska A, Kulmatycki L, Boron-Krupinska K, Torzynska K. Relaxation techniques interventions during physical exercise classes and coping with stress. Hum Mov. 2018;19(3):38-47; doi: https://doi.org/10.5114/hm.2018.76078. 
inability to study on one's own, lack of motivation or skills to learn, and, as a result, school failures, difficulty to meet the excessive requirements at school and the final grading [6].

The most frequent consequences of long-term or intensive stress among the adolescent include [8,9]:

- physical conditions - when students experience a high level of stress, they often suffer from headaches, stomach aches, fatigue, or drowsiness;

- lack of sleep - as a result of many hours of classes to be attended at school and after, students do not have enough sleeping time; this problem affects mostly those who are exhausted with studying and have learning difficulties;

- anxiety and depression - students who live in the environment where the level of felt stress is high experience an elevated level of anxiety, as well as occurring and reoccurring fears, such as fear of darkness, strangers, or loneliness; research shows that young people living under the pressure of success are at risk of depression-related conditions;

- emotional instability - mood swings and inability to control one's emotions have been observed among students who experience high level of stress related to school interactions;

- poor school results - high level of stress in the school environment leads to poor academic results;

- social withdrawal - students at risk of high stress level frequently withdraw from family and social life, spend more time alone, avoid being with relatives or peers;

- illegal drugs and alcohol trials - high stress level facilitates experimenting with various types of illicit substances.

\section{Relaxation techniques in school environment}

At school, there are many situations which may cause stress. Despite the evidence of a positive impact of relaxation techniques on coping with stress by youth, the scope of research in this field is limited, although new information on the subject is published regularly [10]. The majority of projects have been conducted in the clinical area, with focus on interventions; however, in recent years, there has been an increasing interest in applying relaxation techniques at schools.

Students who have attended yoga classes for 12 weeks (4 times a week) show higher resilience to stress, as well as reduced compulsive thinking and emotional arousal in comparison with the control group [11]. Other studies prove better concentration [12] and a decreased anxiety level [13] among adolescent after mindful- ness training. Researchers have discovered that if children develop their skills of being in the present and are able to control their mindfulness, they can cope with stress situations more efficiently. Participants of a mindfulness training conducted at schools in Canada experienced a high level of optimism [14], while students in Hong Kong and the United Kingdom, after the end of the experiment, showed reduced symptoms of depression and stress, as well as a higher level of well-being $[15,16]$.

Many authors point to mental health problems of young people who cannot cope with everyday life requirements $[17,18]$. Therefore it is worthwhile to introduce at schools classes which would show the students how they could calm down, focus on rest from the everyday life affairs. A class including relaxation techniques can be an example of such an activity.

Purpose of the study and the research questions

The aim of the presented study was to answer the question about the impact of relaxation interventions during physical education (PE) classes on the ability to cope with stress. The authors formulated 3 questions:

1. Do the female students of a senior high school in Wrocław cope with stress situations, and to what degree in comparison with the standards?

2 . Is there any difference in coping with stress between groups participating in traditional PE classes and PE classes including relaxation techniques, and if so, to what degree?

3. What is the difference between the study group and the control group with respect to their perceived sense of power and perseverance in exploring selfefficacy?

\section{Material and methods}

The applied study method was a pedagogical experiment, performed with the technique of parallel groups, in a real-life environment. The independent variable and at the same time the experimental stimulus was a PE class including relaxation techniques, and the dependent variable was the capacity to cope with stress.

The studied population of 182 female students was divided into 2 groups - the study group, comprising 122 students, and the control group, involving 60 students.

The differences in the size of the groups were related to the authors' intention to analyse as many ex- 


\section{HUMAN MOVEMENT}

A. Urbanska, L. Kulmatycki, K. Boron-Krupinska, K. Torzynska, Relaxation techniques interventions

perimental groups as possible. The authors also wanted the 2 groups to be led by the same person, to avoid teachers' personality differences and differences in their approach (to the way the class was conducted), which the authors consider a strong part of the research methodology.

The division was made by way of a random allocation of specific class groups to either the study or the control group. This allowed to conduct the research during a regular PE course, following the syllabus for senior high schools.

Owing to the abnormality of the distributions of most analysed variables, nonparametric testing was used.

At the beginning (pre-test) and at the end (posttest) of the experiment, an evaluation of coping with stress was performed in both groups (Figure 1). For the study group, the observed difference between the initial and the final measurement of stress coping assessment was allocated to individual classes. Each person from the study group participated in the introductory class, which explained the basic notions of relaxation, as well as in 11 classes when the relaxation techniques were applied. The classes took place once a week. The 2 other PE classes per week were conducted in a traditional manner. All classes including relaxation techniques remained in compliance with the syllabus.

Female students from the control group participated in traditional PE classes, which took place 3 times a week, over the same period and at the same school. The syllabus was taught in a traditional way. The classes in the study group and in the control group were conducted by the same teacher.
In the pre-tests and post-tests, a standardized research tool, i.e. the Personal Competence Scale (KompOs), was used to assess the stress coping capacity. It is a Polish research tool by Juczyński, 2001. As for its reliability, the internal consistency of the KompOs assessed with Cronbach alpha is 0.72 for the whole scale, 0.74 for the Force subscale, and 0.62 for the Persistence subscale. The reliability of the overall testretest score (after 6 weeks) in a group aged 15 and 17 years was 0.51 . The theoretical validity was determined by correlating the results of KompOs with different criterion measures. Significant correlations were obtained for the sense of self-efficacy (SSE) measured by the General Self-Efficacy Scale (GSES) and for selfesteem measured by the Coopersmith Self-Esteem Inventory (CSEI).

\section{Personal Competence Scale}

The KompOs scale measures the general SSE, also called the sense of personal competence, which refers to personal resources of an individual which they use to cope with problems in various fields of life. KompOs is a research tool applied to study children and youth. It comprises 2 parts (subscales), which refer to specific task situations, formulated half-positive and half-negative. KompOs also allows to obtain results in two subscales regarding the force necessary to initiate an action and the persistence needed to continue an action.

In the KompOs scale, the subtotal is calculated for the general SSE, and a separate analysis measures the factors of power and perseverance. The score may vary from 12 to 48 points in the case of the total re-

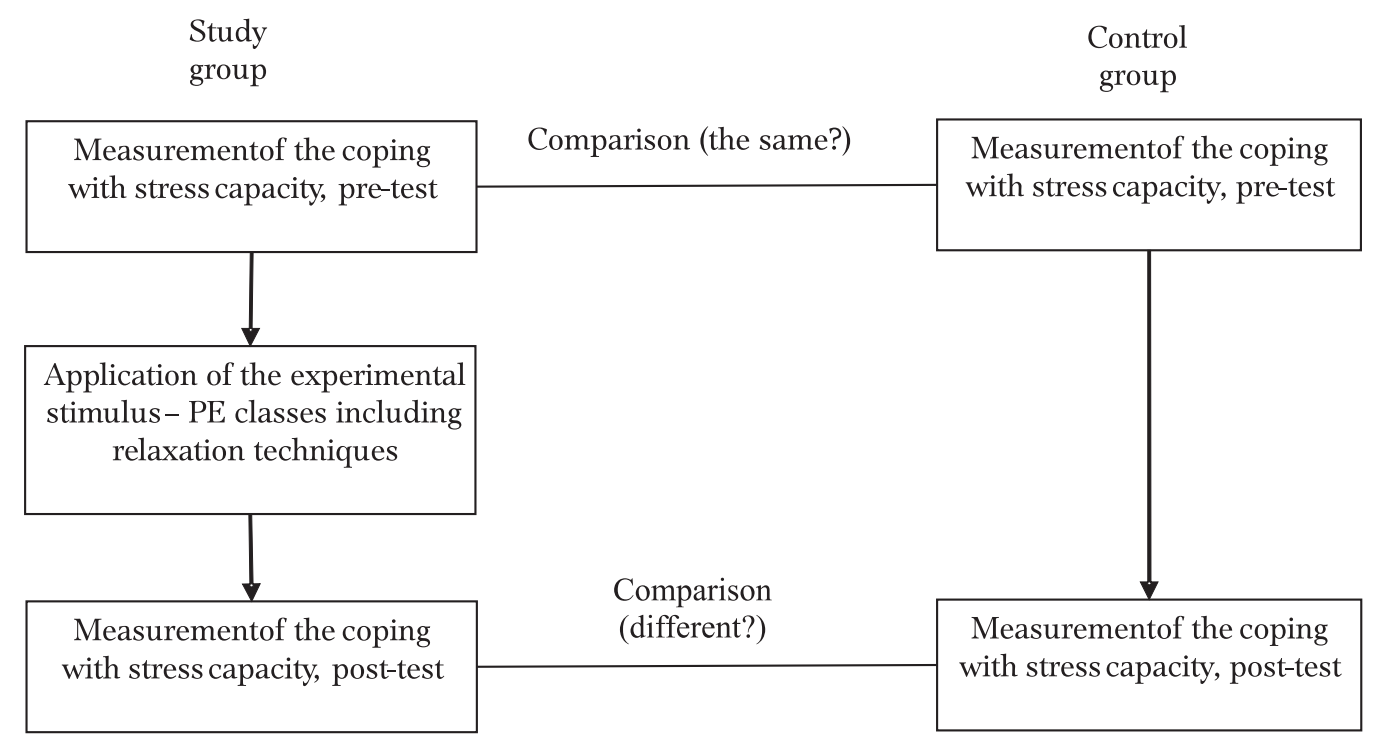

Figure 1. Schematic representation of the pedagogical experiment 
sult for the sense of personal competence, and from 6 to 24 points for each subscale. A higher score is the evidence of a higher SSE, power, or perseverance of an individual. The general score for the sense of personal competence is converted into standard units in sten scores. A respondent may receive a result which is:

- low (from sten 1 to 4 );

- average (from sten 5 to 6);

- high (from sten 7 to 10).

To interpret the results describing the factors of power and perseverance, one should refer to the average results of the standardization test, which was based on a population of 758 children and youth.

\section{Ethical approval}

The research related to human use has been complied with all the relevant national regulations and institutional policies, has followed the tenets of the Declaration of Helsinki, and has been approved by the authors' institutional review board or an equivalent committee.

\section{Informed consent}

Informed consent has been obtained from all individuals included in this study and their legal guardians.

\section{Results}

1. Do the female students of a senior high school in Wrocław cope with stress situations, and to what degree in comparison with the standards?

The level of subjective general SSE in coping with stress was evaluated in accordance with the KompOs scale. The results are presented in Table 1 . The analysis was performed with the use of the Student's $t$-distribution test. The $p$ column presents the probability (significance level), i.e. a comparison of the average results achieved for the Wrocław school with the average values of the standardization test. The calculation assumed normal distribution of the KompOs scale. It can be observed that in all cases, the difference between the corresponding average values is statistically signifi- cant $(p<0.05)$. Female students from the Wrocław school showed a significantly higher average level of the power factor in comparison with the standardization group, but their average level of the perseverance factor was significantly lower. However, if we consider the general result of the KompOs scale, the average value in the group from the Wrocław school was significantly lower than that in the standardization test.

Table 2 presents the percentage distribution of the SSE after conversion to standard units in the sten score, illustrating the level at which the female students of the senior high school coped with stress situations. The result ranging from sten 1 to 4 , which is interpreted as low, was achieved by $30 \%$ of the study group; $40 \%$ of the respondents obtained results ranging from sten 5 to 6 , interpreted as average; a high level of the sense of personal competence, ranging from sten 7 to 10 , was observed in $30 \%$ of students.

The study performed at the Wrocław school revealed that female students did not cope with stress situations well. The average values scored by the respondents (the subtotal result of the SSE and the perseverance factor) were significantly lower than the average values obtained in the standardization test. As far as the power factor is concerned, female students achieved a higher result than the average score from the standardization test. The same share of $30 \%$ of

Table 2. Percentage distribution of the sense of self-efficacy in accordance with the KompOs scale after conversion into standardized units, pre-test (September)

\begin{tabular}{cccc}
\hline Sten & All study group & Result (level) & All study group \\
\hline 1 & $8 \%$ & & \\
2 & $8 \%$ & Low & $30 \%$ \\
3 & $5 \%$ & & \\
4 & $9 \%$ & & \\
5 & $20 \%$ & Average & $40 \%$ \\
6 & $20 \%$ & & \\
7 & $20 \%$ & High & $30 \%$ \\
8 & $6 \%$ & & \\
9 & $3 \%$ & & \\
10 & $1 \%$ & & \\
\hline
\end{tabular}

Table 1. Comparison of results for the sense of self-efficacy (SSE), power, and perseverance (KompOs) with the standardization test

\begin{tabular}{|c|c|c|c|c|c|}
\hline \multirow{2}{*}{ KompOs factor } & \multicolumn{2}{|c|}{ Female students from the Wrocław school } & \multicolumn{2}{|c|}{ Standardization test } & \multirow{2}{*}{$p$} \\
\hline & Average & $S D$ & Average & $S D$ & \\
\hline Power & 17.35 & 3.37 & 16.74 & 3.29 & 0.04 \\
\hline Perseverance & 15.54 & 3.53 & 17.26 & 3.07 & $<0.01$ \\
\hline Subtotal (SSE) & 32.90 & 5.63 & 34.00 & 5.10 & 0.02 \\
\hline
\end{tabular}


A. Urbanska, L. Kulmatycki, K. Boron-Krupinska, K. Torzynska, Relaxation techniques interventions

students referred both to high SSE and low SSE; 40\% of the study group coped with stress situations at an average level.

2. Is there any difference in coping with stress between groups participating in traditional PE classes and PE classes including relaxation techniques, and if so, to what degree?

SSE in coping with stress among the investigated female students was evaluated twice: in September and in December (Table 3). At the beginning of the study, the average value of the general SSE was higher in the control group, i.e. the female students who were to participate in the traditional PE classes scored higher $(\mathrm{SSE}=33.73)$ than those in the study group, i.e. the female students who were to participate in $\mathrm{PE}$ classes including relaxation techniques (SSE $=32.48$ ). However, the difference of the average value between the groups was not statistically significant $(p=0.16)$, so at the beginning of the experiment, there was no statistically significant difference between both groups in their capacity to cope with stress. At the end of the research, the SSE changed in comparison with the initial study. On average, it was higher in the study group $(\mathrm{SSE}=33.29)$ than in the control group $(\mathrm{SSE}=$ $32.57)$, although the difference was not statistically significant ( $p=0.28$ ), as was the case in the pre-test.

As revealed in the September and December tests, the assessment of SSE changed in both groups; however, the directions of the changes were opposite (Table 4). In the study group, the general result in the KompOs scale (SSE) was higher in December $(\mathrm{SSE}=33.29)$ in comparison with the value scored in September (SSE = 32.48), which means that in the period between the tests, the average value increased by 0.81 . In the control group, on the other hand, the December result $(\mathrm{SSE}=32.57)$ was lower than that obtained in September (SSE $=33.73$ ); the average value decreased by 1.17.

The general result of the SSE can be converted to sten score in accordance with the distribution of interim standards defined in the population of 758 people of similar age (boys and girls). Table 5 presents a comparison illustrating the changes of sten distribution in the study group in both tests. At the beginning of the research, $33 \%$ of the study group achieved a low result, while at the end of the experiment this share was reduced by 2 percentage points and amounted to $31 \%$. This resulted from a smaller number of people in sten 1 . The largest difference observed in the period between the tests refers to the group of people who coped with stress at a high level; in this subgroup, the result increased by 4 percentage points (from $26 \%$ to $30 \%$ ). The smallest difference was noted in the group who scored an average result; here, there was a drop by 1 percentage point (from $40 \%$ to $39 \%$ ).

A reverse direction of changes can be observed in the control group (Table 6); the number of female students who coped with stress at a low level increased by 8 percentage points (from $27 \%$ to $35 \%$ ). This resulted from the increased number of people in sten 4 (an increase by 9 percentage points, from $8 \%$ to $17 \%$ ). A significant change in the period between the tests can be observed in the group of respondents who scored a high result; their share decreased by 10 percentage points (from $37 \%$ to $27 \%$ ). As in the study group, the smallest difference can be observed in the group of students with the average result; however, the direction of change is opposite.

Table 3. Comparison of average values for the sense of self-efficacy (SSE) in the study group and the control group in the pre-test (September) and post-test (December)

\begin{tabular}{lccccc}
\hline \multirow{2}{*}{ Test } & \multirow{2}{*}{ SSE } & \multicolumn{2}{c}{ Average values (points) } & \multicolumn{2}{c}{ Mann-Whitney test } \\
\cline { 3 - 6 } & & Study group $(n=122)$ & Control group $(n=60)$ & $Z$ & $p$ \\
\hline September & Subtotal (SSE) & 32.48 & 33.73 & 1.40 & 0.16 \\
December & Subtotal (SSE) & 33.29 & 32.57 & 1.08 & 0.28 \\
\hline
\end{tabular}

Table 4. Changes of the sense of self-efficacy (SSE) in coping with stress (expressed in points of the KompOs scale) during the period between the tests in September and December

\begin{tabular}{lcccccccc}
\hline \multirow{2}{*}{ Group } & \multirow{2}{*}{ SSE } & \multicolumn{2}{c}{ Pre-test (September) } & \multicolumn{2}{c}{ Post-test (December) } & \multicolumn{3}{c}{$\begin{array}{c}\text { Difference between September } \\
\text { and December }\end{array}$} \\
\cline { 3 - 9 } & & Average & $S D$ & Average & $S D$ & Average & $S D$ & $p$ \\
\hline Study & Subtotal (SSE) & 32.48 & 5.64 & 33.29 & 5.08 & 0.81 & 5.38 & 0.431 \\
Control & Subtotal (SSE) & 33.73 & 5.57 & 32.57 & 5.21 & -1.17 & 7.42 & 0.228 \\
\hline
\end{tabular}


Table 5. Distribution of sten values in the study group $(n=122)$ in the pre-test (September) and after 11 PE classes including relaxation techniques (December)

\begin{tabular}{|c|c|c|c|c|c|c|c|c|c|}
\hline \multirow{3}{*}{ Sten } & \multicolumn{4}{|c|}{ Test } & \multirow{3}{*}{ Result } & \multicolumn{4}{|c|}{ Test } \\
\hline & \multicolumn{2}{|c|}{ September } & \multicolumn{2}{|c|}{ December } & & \multicolumn{2}{|c|}{ September } & \multicolumn{2}{|c|}{ December } \\
\hline & $n$ & $\%$ & $n$ & $\%$ & & $n$ & $\%$ & $n$ & $\%$ \\
\hline 1 & 13 & 11 & 6 & 5 & \multirow{4}{*}{ Low } & \multirow{4}{*}{40} & \multirow{4}{*}{33} & \multirow{4}{*}{38} & \multirow{4}{*}{31} \\
\hline 2 & 9 & 7 & 8 & 7 & & & & & \\
\hline 3 & 6 & 5 & 9 & 7 & & & & & \\
\hline 4 & 12 & 10 & 15 & 12 & & & & & \\
\hline 5 & 25 & 20 & 23 & 19 & \multirow{2}{*}{ Average } & \multirow{3}{*}{50} & \multirow{3}{*}{40} & \multirow{2}{*}{48} & \multirow{2}{*}{39} \\
\hline 6 & 25 & 20 & 25 & 20 & & & & & \\
\hline 7 & 22 & 18 & 23 & 19 & & & & & \\
\hline 8 & 6 & 5 & 7 & 6 & \multirow{3}{*}{ High } & \multirow{3}{*}{32} & \multirow{3}{*}{26} & \multirow{3}{*}{36} & \multirow{3}{*}{30} \\
\hline 9 & 4 & 3 & 4 & 3 & & & & & \\
\hline 10 & 0 & 0 & 2 & 2 & & & & & \\
\hline
\end{tabular}

Table 6. Distribution of sten values in the control group $(n=60)$ in the pre-test (September) and after 11 PE classes including relaxation techniques (December)

\begin{tabular}{|c|c|c|c|c|c|c|c|c|c|}
\hline \multirow{3}{*}{ Sten } & \multicolumn{4}{|c|}{ Test } & \multirow{3}{*}{ Result } & \multicolumn{4}{|c|}{ Test } \\
\hline & \multicolumn{2}{|c|}{ September } & \multicolumn{2}{|c|}{ December } & & \multicolumn{2}{|c|}{ September } & \multicolumn{2}{|c|}{ December } \\
\hline & $n$ & $\%$ & $n$ & $\%$ & & $n$ & $\%$ & $n$ & $\%$ \\
\hline 1 & 3 & 5 & 2 & 3 & \multirow{4}{*}{ Low } & \multirow{4}{*}{16} & \multirow{4}{*}{27} & \multirow{4}{*}{21} & \multirow{4}{*}{35} \\
\hline 2 & 5 & 8 & 5 & 8 & & & & & \\
\hline 3 & 3 & 5 & 4 & 7 & & & & & \\
\hline 4 & 5 & 8 & 10 & 17 & & & & & \\
\hline 5 & 11 & 18 & 18 & 30 & \multirow{3}{*}{ Average } & \multirow{3}{*}{22} & \multirow{3}{*}{37} & \multirow{2}{*}{23} & \multirow{2}{*}{38} \\
\hline 6 & 11 & 18 & 5 & 8 & & & & & \\
\hline 7 & 15 & 25 & 8 & 13 & & & & & \\
\hline 8 & 4 & 7 & 4 & 7 & \multirow{3}{*}{ High } & \multirow{3}{*}{22} & \multirow{3}{*}{37} & \multirow{3}{*}{16} & \multirow{3}{*}{27} \\
\hline 9 & 1 & 2 & 4 & 7 & & & & & \\
\hline 10 & 2 & 3 & 0 & 0 & & & & & \\
\hline
\end{tabular}

There was no difference in coping with stress between the groups participating in traditional PE classes and PE classes including relaxation techniques either in the pre-test or in the post-test observation. The difference of average values for the general SSE between the study group and the control group was not statistically significant (in the pre-test or in the posttest). However, in December, the study group achieved higher results than the control group (the result of the study group after $11 \mathrm{PE}$ classes with relaxation techniques - 33.29; the result of the control group - 32.57). In the study group, a small increase of the sense of personal competences was observed after participating in the PE classes including relaxation techniques. In the control group (after 3 months) this value decreased.
3. What is the difference between the study group and the control group with respect to their perceived sense of power and perseverance in exploring selfefficacy?

In the pre-test (September), the sense of power among the subjects from the study group was significantly lower (16.84) in comparison with those from the control group (18.40), as presented in Table 7. In December, after the sequence of PE classes including relaxation techniques, the average level of the sense of power changed in both groups. In the study group, it increased to 17.53; in the control group, it decreased to 17.78. At the beginning of the research, there was a difference between both groups with respect to the sense of power $(p=0.01)$; at the end of the research, there was no statistically significant difference between the groups $(p=0.49)$. 
A. Urbanska, L. Kulmatycki, K. Boron-Krupinska, K. Torzynska, Relaxation techniques interventions

Table 7. Comparison of average values of the sense of power and perseverance in the study group and the control group in the pre-test (September) and post-test (December) observation

\begin{tabular}{|c|c|c|c|c|c|}
\hline \multirow{2}{*}{ Test } & \multirow{2}{*}{$\begin{array}{l}\text { Elements of the } \\
\text { KompOs scale }\end{array}$} & \multicolumn{2}{|c|}{ Average values (points) } & \multicolumn{2}{|c|}{ Mann-Whitney test } \\
\hline & & Study group & Control group & $Z$ & $p$ \\
\hline \multirow{2}{*}{ September } & Power & 16.84 & 18.40 & 2.67 & 0.01 \\
\hline & Perseverance & 15.65 & 15.33 & 0.44 & 0.66 \\
\hline \multirow{2}{*}{ December } & Power & 17.53 & 17.78 & 0.69 & 0.49 \\
\hline & Perseverance & 15.75 & 14.78 & 2.21 & 0.03 \\
\hline
\end{tabular}

Table 8. Changes of the sense of power and perseverance in coping with stress (expressed in points of the KompOs scale) in the period between the tests in September and December

\begin{tabular}{llccccccc}
\hline \multirow{2}{*}{ Group } & \multirow{2}{*}{$\begin{array}{l}\text { Elements of the } \\
\text { KompOs scale }\end{array}$} & \multicolumn{3}{c}{ Pre-test (September) } & Post-test (December) & \multicolumn{3}{c}{$\begin{array}{c}\text { Difference between September } \\
\text { and December }\end{array}$} \\
\cline { 3 - 9 } & & Average & $S D$ & Average & $S D$ & Average & $S D$ & $p$ \\
\hline \multirow{2}{*}{ Study } & Power & 16.84 & 3.50 & 17.53 & 3.01 & 0.69 & 4.07 & 0.061 \\
& Perseverance & 15.65 & 3.47 & 15.75 & 3.38 & 0.10 & 4.67 & 0.801 \\
\hline \multirow{2}{*}{ Control } & Power & 18.40 & 2.84 & 17.78 & 3.42 & -0.62 & 4.42 & 0.285 \\
& Perseverance & 15.33 & 3.69 & 14.78 & 3.55 & -0.55 & 5.38 & 0.431 \\
\hline
\end{tabular}

The perseverance factor in the pre-test observation (September) was similar in the groups, without any statistically significant difference between them ( $p=$ 0.66). However, in the post-test measurement (December), the average level of perseverance was significantly higher in the study group (15.75) in comparison with the control group (14.78) (Table 7). In September, there was no difference between the study group and the control group with respect to the sense of perseverance $(p=0.66)$, while in December, the difference between the groups was statistically significant $(p=0.03)$.

In the period between the tests in September and December, in both groups, the elements of the KompOs scale (power and perseverance) changed; however, the directions of these changes were opposite (Table 8). In the study group, the average assessment of power and perseverance in accordance with the KompOs scale increased in December by 0.69 and 0.10 , respectively. In the control group, these average values decreased in December in comparison with the September score (the difference of -0.62 and -0.55 , respectively).

In September, there was a difference between the groups with respect to the sense of power in exploring self-efficacy. The average value of the power factor in the study group was significantly lower than in the control group. However, in December, the average level of the sense of power in both groups changed, and the difference between the study group and the con- trol group turned out not statistically significant. An opposite direction of changes can be observed for the perseverance factor in exploring self-efficacy. In September, both groups achieved similar results, which were not statistically different. In December, however, the average level of perseverance in the study group was significantly higher in comparison with that in the control group.

In the study group, the sense of power and perseverance achieved higher average values after the end of the experiment in comparison with the pre-test results. In the control group, on the other hand, we can observe a drop in the values of the factors of power and perseverance in exploring self-efficacy. However, these differences are very small, therefore one should be careful when formulating the final conclusion.

\section{Discussion}

Young people at puberty are in a special moment of their lives when they get ready for adulthood. It is a very important period because apart from physical and mental changes, intensive individual development takes place, focused on success. This is related to a high level of stress, with which young people are not able to cope. An additional factor having a negative impact on the adolescent is the modern fast pace of life, where there is no time for resting, reflecting, or just talking to a dear person. Also at school, stu- 
dents feel a permanent pressure related to exams and tests. A positive stress which facilitates the development and motivation to learn transforms into a negative, chronic stress resulting from the transgression of limits of a student's capacities.

The research conducted in one of the schools in Wrocław, Poland, shows that young people have problems with coping with challenging situations. By various forms of communication, such as verbal expression or inadequate behaviour, they crave for help from adults and peers. However, in difficult moments of their lives, many students do not receive any support from their families, while among peers, they most often encounter 'unhealthy' ways of coping with stress, consisting in the usage of various types of intoxicating substances (smoking, alcohol consumption, etc.). School should be the right environment to learn about the 'healthy' methods of coping with stress.

The sequence of PE classes with relaxation interventions was an opportunity for the adolescent to experience specific techniques which may constitute a positive alternative for the most common, yet unhealthy ways of coping with stress. The analysis of the achieved results allowed to assess the impact of these classes on the female students from a senior high school. In post-tests, the girls from the study group achieved higher results of dependent variables in comparison with the pre-tests. On the other hand, in the course of the school year, we observed an opposite direction of changes in the control group. The effectiveness of coping with stress depends on both the situational factors related to challenging circumstances experienced in life and the subjective factors related, for example, to resources that a person has to their disposal [19].

In the presented research, the PE classes including relaxation techniques helped the youth from the study group to act with more perseverance in coping with challenges. A similar project, which lasted 5 weeks and was based on mindfulness and tai chi techniques, was conducted in public schools in Boston. The 5-week program demonstrated that sustained interest in this area in middle school-aged boys and girls was possible. The observations of the analysed group made in the process suggested that the subjects experienced well-being, calmness, relaxation, improved sleep, less reactivity, increased self-care and self-awareness [20]. The results of a study carried out among students of a senior high school in the United States indicate a decreased level of stress and anxiety, increased selfconfidence and health-promoting behaviour, as well as an increased sense of control among those who par- ticipated in the relaxation interventions in comparison with students who had traditional PE classes [21]. During the research programme, students participated in $8 \mathrm{PE}$ classes including various relaxation techniques, such as meditation, progressive relaxation, yoga, mindfulness, visualisation, and concentration on breath.

Another research, conducted in a group of 522 students from 12 senior high schools in the United Kingdom, has proven the effectiveness of the mindfulness training in coping with stress. For the purpose of the experiment, schools and class groups were selected where teachers already had experience in mindfulness training. It might have indicated, however, that the students had occasionally come across such type of classes previously. The study results show that after 3 months, there was an increased level of well-being and reduced level of felt stress. Furthermore, the effects were maintained for 2 months after the end of the programme, during the summer exams [16]. Also other research conducted in the United States indicated that young people who participated in relaxation classes with elements of yoga were more capable of coping with stress, showed lower emotional agitation, and experienced fewer obsessive thoughts [11]. The research showed that such classes were attractive for students and their effects were assessed positively by the school management, parents, and teachers. The researchers stress that to achieve positive lasting effects, it is necessary to secure high attendance of students in the classes including relaxation techniques, and they postulate greater cooperation between parents, tutors, and teachers of relaxation classes.

Issues related to stress are relevant to any stage of human growth. Research focused on mental health of children and youth has been rapidly progressing in recent years. An increasing demand for various methods and forms of supporting the development of young people and counteracting mental problems requires the 'anti-stress' concepts to be worked out accordingly. School is a perfect place to conduct such interventions and to introduce prevention programmes, since numerous stressors are directly related with this environment.

\section{Conclusions}

The research results lead to the following conclusions:

1. According to the research conducted in a group of 182 female students of a senior high school in Wrocław, Poland, teenage girls experience problems with coping with stressful situations. The average values of the ana- 
A. Urbanska, L. Kulmatycki, K. Boron-Krupinska, K. Torzynska, Relaxation techniques interventions

lysed variables (the general result of the SSE and the perseverance factor) are significantly lower from those of the standardization test of the KompOs scale.

2 . In the study group, where relaxation techniques were applied, one may observe a slight increase of the value of the sense of personal competence, contrary to the control group, where the value decreased. However, the difference is not statistically significant.

3. In comparison with the pre-test results (September), where the average value of the power factor in the study group was significantly lower than in the control group, in the post-test (December), the average level of the sense of power evened out in both groups. However, with respect to the perseverance factor, in comparison with the pre-test results (September), where there was not any difference between the study group and the control group, in the post-test (December), the average level of this factor was higher in the group of students participating in PE classes including relaxation techniques. However, the difference between the groups was not statistically significant.

To conclude, it may be stated that the authors of the research are aware of many shortcomings of the experiment conducted in a real-life school environment. The limitations refer to numerous mediation variables which occurred during the educational and didactic process, as well as to the limited impact time of the independent variable. Nevertheless, when searching for effective ways of reducing stress at school, it is necessary to test innovative ways of working with the youth. The presented study is one of such attempts.

\section{Disclosure statement}

No author has any financial interest or received any financial benefit from this research.

\section{Conflict of interest}

The authors state no conflict of interest.

\section{References}

1. Stallard P, Taylor G, Anderson R, Daniels H, Simpson N, Phillips R, et al. School-based intervention to reduce anxiety in children: study protocol for a randomized controlled trial (PACES). Trials. 2012;13:227; doi: 10.1186/1745-6215-13-227.

2. Hauber RP, Rice MH, Howell CC, Carmon M. Anger and blood pressure readings in children. Appl Nurs Res. 1998;11(1):2-11; doi: 10.1016/S0897-1897(98)80021-9.

3. Muris P, Meesters C, Morren M, Moorman L. Anger and hostility in adolescents: relationships with self-reported attachment style and perceived parental rearing styles. J Psychosom Res. 2004;57(3):257-264; doi: 10.1016/ S0022-3999(03)00616-0.
4. Goldston DB, Daniel S, Reboussin DM, Kelly A, Ievers C, Brunstetter R. First-time suicide attempters, repeat attempters, and previous attempters on adolescent inpatient psychiatry unit. J Am Acad Child Adolesc Psychiatry. 1996;35(5):631-639; doi: 10.1097/00004583199605000-00018.

5. Greenberg MT, Weissberg RP, O’Brien MU, Zins JE, Fredericks L, Resnik H, et al. Enhancing school-based prevention and youth development through coordinated social, emotional, and academic learning. Am Psychol. 2003;58(6-7):466-474; doi: 10.1037/0003-066X.58.67.466 .

6. Suldo SM, Shaunessy E, Hardesty R. Relationships among stress, coping, and mental health in high-achieving high school students. Psychol Schools. 2008;45(4): 273-290; doi: 10.1002/pits.20300.

7. Talik E. Specyfika stresu szkolnego i strategie radzenia sobie $z$ nim przez młodzież w okresie dorastania. Horyz Psychol. 2011;1(1):127-137.

8. Conner J, Pope D, Galloway M. Success with less stress. Educ Leadership. 2009;67(4):54-58.

9. Copeland EP. Stress in children and adolescents: tips for parents. National Association of School Psychologists; 2008.

10. Harnett PH, Dawe S. The contribution of mindfulnessbased therapies for children and families and proposed conceptual integration. Child Adolesc Ment Health. 2012;17(4):195-208; doi:10.1111/j.1475-3588.2011. 00643.x.

11. Mendelson T, Greenberg MT, Dariotis JK, Gould LF, Rhoades BL, Leaf PJ. Feasibility and preliminary outcomes of a school-based mindfulness intervention for urbanyouth. JAbnorm Child Psychol. 2010;38(7):985994; doi: 10.1007/s10802-010-9418-x.

12. Napoli M, Krech PR, Holley LC. Mindfulness training for elementary school students: the attention academy. J Appl School Psychol. 2005;21(1):99-125; doi: 10.1300/J370v21n01_05.

13. Jennings SJ, Jennings JL. Peer-directed, brief mindfulness training with adolescents: a pilot study. Int J Behav Consult Ther. 2013;8(2):23-25; doi: 10.1037/ h0100972.

14. Schonert-Reichl KA, Lawlor MS. The effects of a mindfulness-based education program on pre- and early adolescents' well-being and social and emotional competence. Mindfulness. 2010;1(3):137-151; doi: 10.1007/ s12671-010-0011-8.

15. Lau N, Hue M. Preliminary outcomes of a mindfulness-based programme for Hong Kong adolescents in schools: well-being, stress and depressive symptoms. Int J Child Spirituality. 2011;16(4):315-330; doi: 10.1080/1364436X.2011.639747.

16. Kuyken W, Weare K, Ukoumunne OC, Vicary R, Motton N, Burnett R, et al. Effectiveness of the mindfulness in schools programme: non-randomised controlled feasibility study. Br J Psychiatry. 2013;203(2):126131; doi: 10.1192/bjp.bp.113.126649. 
17. Shonkoff JP, Boyce WT, McEwen BS. Neuroscience, molecular biology, and the childhood roots of health disparities: building a new framework for health promotion and disease prevention. JAMA. 2009;301(21): 2252-2259; doi: 10.1001/jama.2009.754.

18. Sun RCF, Shek DTL. Life satisfaction, positive youth development, and problem behaviour among Chinese adolescents in Hong Kong. Soc Indic Res. 2010;95(3): 455-474; doi: 10.1007/s11205-009-9531-9.

19. Talik E, Szewczyk L. Wybrane zasoby osobiste a strategie radzenia sobie ze stresem u nastolatków. Pol Forum Psychol. 2010;15(2):154-168.

20. Wall RB. Tai chi and mindfulness-based stress reduction in a Boston public middle school. J Pediatr Health Care. 2005;19(4):230-237; doi: 10.1016/j.pedhc.2005.02.006.

21. Foret MM, Scult M, Wilcher M, Chudnofsky R, Malloy L, Hasheminejad N, et al. Integrating a relaxation response-based curriculum into a public high school in Massachusetts. J Adoles. 2012;35(2):325-332; doi: 10.1016/j.adolescence.2011.08.008. 